\title{
KEWIRAUSAHAAN DALAM PERSPEKTIF ONTOLOGY
}

\author{
Rusnandari Retno Cahyani ${ }^{1)}$, Mugi Harsono ${ }^{2)}$ \\ 1) Staf pengajar Universitas Sahid Surakarta \\ Mahasiswa PDIE Universitas Sebelas Maret \\ rusnandarirc@gmail.com; rusnandarirc@student.uns.ac.id \\ ${ }^{2)}$ Staf Pengajar FEB-Universitas Sebelas Maret \\ mugiharsono_fe@staf.uns.ac.id
}

\begin{abstract}
This article explores the domain of entrepreneurial research by thematically mapping and assessing the intellectual area of the field. Existing reviews show that the body of knowledge of entrepreneurship is growing, and while important contributions to theoretical and methodological integration are proven, the field is described as phenomenal based, potentially fragmented and suffering from theoretical shortcomings. Based on that entrepreneurship encompasses a variety of entrepreneurial developments throughout the country, we identify 44 relevant journal articles published in the 2009-2018 period. We inventory the development domain of entrepreneurship to provide relevant and comprehensive research organizations. This involves examining the subject of Entrepreneurship research, and inductively synthesizing and categorizing it into the main themes and sub-themes. As such, we offer reliable, ontologically constructed, and practically useful resources. From this basis, we discuss phenomena, problems, inconsistencies, and temporary debates in which new theories of entrepreneurship continue to develop and research can be done. We conclude that Entrepreneurship has several thematic fields that are coherent and rich in potential for future research and theory development.
\end{abstract}

Keywords: Entrepreneurship, Ontology, Green Entrepreneurship, Social Entrepreneurship, International Entrepreneurship, Entrepreneurship Education 
EKONOMI BISNIS DAN KEWIRAUSAHAAN

Vol. VIII, No. 1, Januari 2019

\section{Pendahuluan}

Kewirausahaan dianggap sebagai kekuatan penggerak ekonomi, memastikan pertumbuhan ekonomi, inovasi teknologi dan organisasi, dan tempat kerja baru. kewirausahaan merupakan sebuah penilaian, eksploitasi peluang akan produk dan jasa baru, layanan atau proses produksi; strategi baru dan bentuk organisasi dan pasar baru untuk produk dan input yang sebelumnya tidak ada. Peluang kewirausahaan adalah peluang ekonomi yang tidak terduga, belum dinila dan ada karena agen yang berbeda memiliki ide yang berbeda pada nilai relatif sumber daya atau ketika sumber daya tersebut diubah dari input menjadi output. melalui penciptaan organisasi baru.

Alvarez et al. (2013) artikel mengartikulasikan paradigma yang berbeda, yang secara sosial dibangun oleh pengusaha melalui tindakan mereka saat mereka berinteraksi dengan konteks dan yang lainnya dalam proses pembentukan peluang. Shen et al ( 2013) bahwa kewirausahaan membutuhkan individu untuk lebih berupaya dan meluangkan waktu bisnis, yang akan mengakibatkan penurunan kesehatan fisik dalam jangka panjang. Untuk merangsang kewirausahaan, saran tentang meningkatkan pendapatan relative dan kondisi kesehatan untuk wiraswasta dibuat untuk referensi pembuat kebijakan.

Kewirausahaan juga mencakup kewirausahaan migran sebagaimana penelitian Neville et al. (2014) perusahaan migran umumnya tidak berkinerja lebih baik daripada perusahaan non-migran dan perusahaan yang dimiliki oleh imigran sering kali kinerjanya buruk; perusahaan migran yang mengekspor ternyata berkinerja lebih baik. Dalam hal ini, langkah-langkah khas dalam kinerja perusahaan seperti pengalaman, Namun, kelompok-kelompok seperti itu jarang muncul dalam perdebatan kontemporer tentang kewirausahaan, selain dalam beberapa penelitian penting (Edwards et al. 2016; Ram et al. 2008). Perubahan dalam ekonomi saat ini telah diidentifikasi bergerak dari kegiatan berbasis pengetahuan ke kreativitas, inovasi, kewirausahaan dan imajinasi (van den Broeck et al., 2008; Oke et al., 2009). Fillis \& Rentschler (2010) bahwa ada hubungan yang jelas antara kreativitas, kewirausahaan dan bidang terkait seperti inovasi dalam hal membangun keunggulan kompetitif bagi organisasi. Profitabilitas harus diukur tidak hanya dalam hal moneter, tetapi juga dalam kaitannya dengan dimensi seperti kekayaan sosial atau modal. Kontribusi wirausaha pada kreativitas dapat membantu melanggar aturan konvensi, atau di paling tidak, merentangkan batas-batas mereka untuk mencapai keberhasilan sekaligus peningkatan yang baik.

\section{Kewirausahaan Hijau/ Green Entrepreneurship}

Gevrenova (2015) Kewirausahaan "hijau" adalah perusahaan yang memproduksi produk ramah lingkungan, untuk mengurangi pengeluaran mereka dan menggunakan sumber daya alam secara berkelanjutan, harus mengadopsi teknik 
EKONOMI BISNIS DAN KEWIRAUSAHAAN

Vol. VIII, No. 1, Januari 2019

penghematan penggunaan energi. Kewirausahaan hijau didefinisikan sebagai upaya untuk meminimalkan jejak lingkungan, yaitu total biaya lingkungan dan sosial yang diakibatkan oleh aktivitas kewirausahaan manusia (Hall et al., 2010). Perusahaanperusahaan hijau sadar akan biaya, inovasi dan keuntungan pemasaran dan mencari perubahan sosial dan moral di sektor wirausaha. Ada dua jenis perusahaan, ini yang menghasilkan produk hijau dan yang menggunakan teknik hijau di jalur produktif. Semua jenis perusahaan hijau berkontribusi dalam masyarakat yang berkelanjutan (Guziana, 2011). penciptaan manfaat ekonomi dan ekonomi Thompson et al. (2011).

Penelitian tentang "kewirausahaan hijau" telah dimulai sekitar dekade terakhir abad yang lalu. Biasa disebut sebagai "hijau" (1), ia juga disebut "kewirausahaan eko" (2), "kewirausahaan ekologis" (3), dan "keberlanjutan kewirausahaan" (4). Namun, semakin banyak sumber daya sastra tentang masalah ini, tidak berfokus pada gagasan "hijau" itu sendiri, tetapi pada penciptaan definisi yang diterima luas tentang hal itu dan dengan demikian melemahkan tujuan utamanya - melestarikan lingkungan. Isaak (5) mendefinisikan "kewirausahaan hijau" sebagai suatu sistem yang mengubah bisnis yang terlibat secara sosial dan lingkungan melalui inovasi signifikan1. Dean dan McMullen di sisi lain, menggambarkannya sebagai proses mendefinisikan dan menemukan kemungkinan ekonomi agar kegagalan dalam aspek ekologi dapat diperbaiki. Shaltegger (6) berpikir tentang "kewirausahaan hijau" (ia berbicara tentang "ecoentrepreneurship") sebagai menciptakan nilai di seluruh "inovasi dan produk ekologi". Selain itu, menurut pendapatnya, kebutuhan tersebut harus berorientasi pasar dan untuk mengekspresikan motivasi pengusaha untuk tetap "ramah lingkungan". Ilmuwan Australia Michael Schaper (7), yang dikenal karena penelitian mendalamnya di bidang bisnis ekologi, merangkum berbagai aspek untuk membentuk konsep keseluruhan untuk "kewirausahaan hijau".

Kewirausahaan ramah lingkungan dapat didefinisikan sebagai perusahaan baru yang memulai dalam jasa lingkungan atau industri produksi, yang berfokus pada sumber daya alam atau kondisi alam seperti ekowisata, daur ulang, pengolahan air limbah, dan keanekaragaman hayati (Nikolaou et al.2011). pergeseran paradigma produksi dan konsumsi terhadap produk dan layanan hijau pada akhirnya membutuhkan kewirausahaan 'hijau' di pasar (Farinelli et al., 2011). Tren perusahaan baru (Chigrin, 2014; Chygryn, 2016) yang berusaha mengatasi tantangan ini menunjukkan bahwa berfungsinya perusahaan secara berkelanjutan dimungkinkan adanya kesepakatan bersama pada kepentingan sosial-ekonomi dan ekologis mereka. Pengusaha hijau atau ecopreneur sebagai pemecah masalah lingkungan dan agen perubahan sosial juga dapat ditunjukkan untuk menargetkan solusi pada tingkat yang berbeda, selaras dengan Zahra et al. (2009) kategorisasi.

\section{Kewirausahaan Sosial/ Social Entrepreneurship}

Dacin et al. (2010) menyimpulkan bahwa kewirausahaan sosial berdasarkan karakteristik dan proses dan kegiatan di tingkat individu akan mengarah pada diskusi 
EKONOMI BISNIS DAN KEWIRAUSAHAAN

Vol. VIII, No. 1, Januari 2019

dan debat yang lebih banyak lagi tentang apa yang seharusnya menjadi karakteristik ini; ini adalah debat yang tidak pernah dapat diselesaikan, karena tidak mungkin bahwa seperangkat karakteristik definitif dapat diterapkan untuk semua jenis kegiatan kewirausahaan sosial di semua konteks.

Dacin et al. (2011) kewirausahaan sosial sebagai domain penelitian di hak pribadi. Perdebatan seputar konsep kewirausahaan sosial dan menyarankan agar fokus pada hasil (positif dan negatif) dan konteks merupakan yang paling bermakna cara memahami istilah, baik secara teoritis maupun secara empiris. Kewirausahaan sosial memiliki potensi untuk menambah dan memperluas teori organisasi dan karena itu menjanjikan sebagai domain dengan menyarankan lima kemungkinan jalan untuk membangun teori di berbagai tingkat analisis institusi dan sosial gerakan, jaringan, budaya, identitas dan gambar, dan pengartian.

Huybrechts dan Nicholls (2012) menyatakan bahwa kewirausahaan sosial adalah proses dinamis yang melaluinya tipe individu tertentu, yang pantas disebut "wirausaha sosial", menciptakan dan mengembangkan organisasi yang dapat didefinisikan sebagai "perusahaan sosial."Sekolah "usaha sosial" berfokus pada organisasi nirlaba yang semakin mencari sumber daya baru dari pasar dan berusaha untuk mengadopsi perilaku yang lebih efisien dan berorientasi pasar (Huybrechts dan Deffourny, 2010). Kegiatan Kewirausahaan Sosial memiliki efek ekonomi yang jauh meningkatkan pertumbuhan, mengurangi kemiskinan dan meningkatkan pembangunan sosial skala besar (Zahra, Gedajlovic, Neubaum dan Shulman, 2009).

Kami mendefinisikan lima tahap kewirausahaan sosial/ Social Entrepreneurship (SE) sebagai berikut. Tahap 1: Mendefinisikan Masalah Sistemik adalah menyatakan masalah yang berasal dari keseluruhan sistem sosial, mis., Akar penyebab ketidaksetaraan, ketidakamanan manusia, atau krisis keberlanjutan global. Tahap 2: Perusahaan Perorangan adalah kegiatan semata-mata oleh pendiri (atau, cofounder) dari sebuah perusahaan sosial. Perusahaan Pengorganisasian adalah kegiatan oleh tim perusahaan sosial/ Theory of Change(ToC) yang memanfaatkan kewirausahaan sosial. Tahap 4: Perusahaan Sosialisasi adalah suatu kegiatan oleh para pemangku kepentingan dalam masyarakat yang berusaha untuk memecahkan masalah sistemik secara kolektif. Tahap 5: Mencapai Perubahan Sistemik adalah mewujudkan perubahan mendasar pada tingkat sistem sosial, yang mencegah atau mengurangi masalah sistemik itu sendiri.

Rivera-Santos et al. (2015) mengusulkan empat dimensi kontekstual yang terdiri dari: kemiskinan akut, informalitas, sejarah kolonial, dan identitas kelompok etnis sebagai faktor lingkungan Kewirausahaan Sosial di Afrika sub-Sahara. Kewirausahaan sosial di negara transit berbeda dari apa yang diakui di sebagian besar negara maju (Fayolle dan Matlay, 2010). Westlund (2012) menunjukkan bahwa kelompok kepentingan sipil menghasilkan modal sosial yang menguntungkan di sisi penawaran dalam kondisi kewirausahaan yang beragam. Ini terdiri dari enam jenis kewirausahaan (ekonomi, akademik, sipil, inovatif, sosial dan politik) menjadi sumber potensial pasokan yang beragam. Bahkan, perbaikan masalah sosial tertentu 
EKONOMI BISNIS DAN KEWIRAUSAHAAN

Vol. VIII, No. 1, Januari 2019 sangat mendasar untuk misi usaha sosial sehingga dikatakan "dimasukkan" ke dalam model bisnis organisasi (Boyd, Henning, Reyna, Wang, Welch, 2009).

Sedangkan menurut Bacq dan Janssen (2011) mencatat bahwa "pengaruh lingkungan eksternal pada individu, proses dan organisasi hanya menerima sedikit, jika tidak untuk mengatakan tidak, perhatian dalam literatur kewirausahaan sosial. Littlewood dan Holt (2015) pengusaha sosial dalam kasus-kasus ini memiliki modal sosial yang signifikan, memiliki posisi keuangan yang relatif baik untuk memulai usaha mereka, dan memiliki pengetahuan, keterampilan, dan pengalaman yang relevan untuk dimanfaatkan. Ini tidak berarti bahwa mereka belum, dan tidak terus, mengatasi kesulitan yang signifikan; misalnya, satu wirausahawan sosial menggambarkan bagaimana mereka "tidak dibayar untuk apa pun yang mereka lakukan," sementara yang lain memilih untuk pindah dengan keluarganya ke komunitas kota. kewirausahaan sosial sebagai proses yang objek utamanya adalah untuk menciptakan nilai sosial), membawa perubahan sosial yang positif (Bacq \& Janssen, 2011), atau menantang status quo (Light, 2009), sejalan dengan ide kewirausahaan sebagai terlibat dalam proses perubahan sosial (Fayolle \& Matlay, 2009) yang studi perlu dikaitkan dengan agenda sosial, budaya, sipil dan politik (Chell et al., 2010). Artinya, studi tentang inisiatif kewirausahaan sosial memiliki potensi untuk menempatkan dimensi sosial dan politik dari proses pengorganisasian tahap-pusat.

\section{Kewirausahaan Internasional/ International Entrepreneurship}

Perkembangan historis Kewirausahaan Internasional sebagai bidang studi, dan menunjukkan bagaimana konsepnya membantu dalam menjawab pertanyaan mendasar tentang bisnis dan kewirausahaan internasional. Selain itu, wawasan disediakan untuk calon peneliti yang tertarik pada International Entrepreneurship / IE, karena bidang tematik untuk penelitian eksplorasi di masa depan dibahas. Karya analitik dalam makalah ini membuat referensi ke literatur yang ada tentang International Entrepreneurship / IE, dan menggunakan Jones, Coviello dan Tang (2011) kategorisasi tema dan sub-tema untuk menggambarkan perkembangan historis International Entrepreneurship / IE, yang menciptakan dasar untuk analisis tentang bagaimana konsep International Entrepreneurship / IE terkait dan terhubung dengan teori bisnis dan kewirausahaan internasional yang mendasar.

Kelompok tematik ketiga - konsep pengenalan peluang yang relative cukup baru adalah International Entrepreneurship/ IE. Chandra et al. (2009) menemukan bahwa penemuan lebih tipikal pengusaha tanpa pengalaman internasional sebelumnya, dan mereka yang memiliki pengalaman dan pengetahuan internasional lebih cenderung mengenali peluang. Proses kewirausahaan yang berkelanjutan dan kreatif di mana manajer kewirausahaan diserap ke dalam komunitas sosial yang muncul dari usaha internasional (Mainela dan Puhakka, 2009). Casillas et al. (2009) berpendapat bahwa kecepatan di mana perusahaan meluncurkan ke pasar internasional secara positif terkait dengan kapasitas daya serapnya dan sejauh mana pengetahuan baru dan sebelumnya sesuai. 
EKONOMI BISNIS DAN KEWIRAUSAHAAN

Vol. VIII, No. 1, Januari 2019

Penelitian kewirausahaan internasional (IE) semakin merefleksikan isu-isu strategis dan tantangan yang dihadapi perusahaan-perusahaan wirausaha ketika mereka mengenali dan menangkap peluang di pasar asing dalam praktik perusahaan, usaha kecil dan menengah (UKM) berusaha untuk mendapatkan pijakan di pasar di seluruh perbatasan nasional, dalam upaya untuk tetap menguntungkan dan tumbuh (Schneider dan Spieth 2013). Mereka melakukannya dengan memodifikasi produk, layanan, dan Model Bisnis mereka untuk memenuhi persyaratan pasar ini (Onetti et al. 2012; Child et al. 2017). Oleh karena itu, UKM dengan sengaja mengukir strategi untuk membangun nilai berkelanjutan dan berkelanjutan untuk kesejahteraan (Aspara et al. 2010).

Dalam mengeksplorasi International Entrepreneurship (IE) fenomena ini adanya kombinasi kegiatan kewirausahaan seperti pencarian peluang dan eksploitasi, inovasi, proaktif, dan perilaku pencarian risiko dari para pengusaha melintasi batas negara (Zucchella et al. 2018). Demikian pula, penelitian tindakan kewirausahaan dan efek dari kegiatan internasionalisasi mereka di pasar luar negeri bersama variabel-variabel lain, seperti perubahan organisasi, Inovasi model bisnis dan kinerja akan sangat berharga untuk memajukan penelitian kewirausahaan internasional (IE) (Jantunen et al. 2005; Zucchella et al. . 2018). Model bisnis, dan penelitian kewirausahaan internasional (IE), secara umum, akan mencapai tonggak sejarah dengan memasukkan konstruksi orientasi strategis lainnya.

\section{Kewirausahaan Pendidikan / Education Entrepreneurship}

Mempertimbangkan kondisi pengetahuan saat ini dalam pendidikan kewirausahaan (lihat, misalnya, Neck dan Greene, 2011; Fayolle, 2013) baru-baru ini menyerukan pendekatan pragmatis dan kritis dalam pengembangan perspektif masa depan tentang penelitian pendidikan kewirausahaan yang menekankan pentingnya membangun landasan teori , menjembatani disiplin dan komunitas (penelitian dan praktik) dan meningkatkan perspektif pemikiran kritis dalam kaitannya dengan lapangan.

Beberapa literatur sistematis mengulas pendidikan kewirausahaan (Byrne et al., 2014; Fayolle, 2013; Ge dan Peng, 2012; Mwasalwiba, 2010; Naia et al., 2014), yang mengarah pada temuan berikut: pertama, tawaran dalam pendidikan kewirausahaan meningkat secara konstan tetapi tetap terfragmentasi; kedua, tujuan pedagogis dan hasil yang diharapkan adalah rumit dan sulit untuk didefinisikan tanpa konsensus luas tentang sifat fenomena kewirausahaan dan keterampilan lunak yang terkait; dan ketiga, studi yang tersedia sebagian besar bersifat deskriptif. Dengan demikian, mereka tidak menjelaskan apakah metode dan pendekatan pengajaran disesuaikan dengan berbagai jenis peserta didik dan hasil yang diharapkan atau faktor kontekstual apa yang berkontribusi terhadap peningkatan efektivitas.

Penelitian yang menunjukkan bahwa Pelatihan Pendidikan Kewirausahaan kadang-kadang dapat dikaitkan secara negatif dengan hasil yang disebutkan di atas. Untuk contoh, Oosterbeek et al. (2010) mengukur niat kewirausahaan di kalangan 
EKONOMI BISNIS DAN KEWIRAUSAHAAN

Vol. VIII, No. 1, Januari 2019

mahasiswa sarjana sebelum dan setelah mereka menyelesaikan kursus kewirausahaan.

\section{Kesimpulan dan penelitian yang akan datang}

Artikel ini memiliki beberapa keterbatasan, yang juga menyajikan area potensial untuk penelitian masa depan. Dalam studi ini, Pendekatan yang membahas konsep-konsep yang menyangkut substansi, proses, waktu, ruang, kausalitas, hubungan budi dan materi, serta status dari entitas-entitas teoritis. Eksplorasi konseptual selama dua dekade menghasilkan kontribusi yang berharga dan memunculkan munculnya aliran pemikiran yang berbeda, tetapi eksplorasi ini tidak memberikan kesatuan dalam definisi konsep dan penetapan batas. Meskipun kurangnya persatuan dapat dianggap sebagai penghalang bagi pengembangan kewirausahaan sosial sebagai bidang penyelidikan ilmiah, masih dapat diperdebatkan apakah suatu konstruksi tunggal yang bersatu dapat dicapai. Selama kesepakatan tentang konsep itu kurang, ada baiknya memberi perhatian besar pada penjelasan tentang apa yang dibutuhkan kewirausahaan sosial ketika menerapkan konsep tersebut. Anehnya, ini tidak terjadi di semua studi dalam pembahasan artikel ini. Inventarisasi definisi yang digunakan di seluruh artikel memberi kami beberapa celah, artikel yang tidak memberikan deskripsi tentang apa yang dimaksud dengan kewirausahaan sosial, wirausahawan sosial, atau perusahaan sosial. Meskipun kurangnya kesatuan dalam pembentukan konsep merupakan halangan untuk pengujian teori yang ketat dan membangun teori, perumusan konsep sistematis yang cocok untuk penelitian empiris dapat ditingkatkan dengan menjelaskan karakteristik yang menentukan, seperti yang digunakan untuk menggambarkan ilmuwan yang berbeda pemikiran atau konsep.

Kami berpendapat bahwa penyelidikan kualitatif mendalam tentang pendorong lain dari perubahan model bisnis seperti pengakuan peluang, kemampuan dinamis, logika pengambilan keputusan, dan mekanisme yang melaluinya mereka memengaruhi kinerja internasional (lihat Zott dan Amit 2010; Foss dan Saebi 2017; Guo et al. 2017) akan menghasilkan data yang lebih kaya di mana dinamika inovasi model bisnis (BMI) dalam kewirausahaan internasional dapat dipelajari. Kami mengkonfirmasi bahwa BMI didorong oleh kewirausahaan orientasi(OE), keputusan manajerial, dan kemampuan untuk menerapkan perubahan untuk memanfaatkan peluang untuk mendapatkan keunggulan kompetitif (lih. Doz dan Kosonen 2010; Michea 2016). Penelitian lebih lanjut juga dapat mengeksplorasi kegiatan manajerial, kegiatan organisasi, dan pendorong lainnya yang dapat mempengaruhi perubahan Model Bisnis dalam internasionalisasi UKM. 
EKONOMI BISNIS DAN KEWIRAUSAHAAN

Vol. VIII, No. 1, Januari 2019

Penelitian yang akan datang juga perlu membahas lebih detail ketidakkonsistenan, dan perdebatan sementara dari domain kewirausahaan, tidak hanya terbatas pada perkembangan kewirausahaan hijau/ green entrepreneurship (GE), kewirausahaan sosial/ social entrepreneurship, Kewirausahaan Internasional/ International Entrepreneurship, Kewirausahaan Pendidikan/Education Entrepreneurship akan tetapi penelitian selanjutnya membahas tentang Women Entrepreneurship, Entrepreneurship intention, dan entrepreneurship perspective.

\section{Daftar Pustaka}

Alvarez, S. A., Barney, J. B., \& Anderson, P. 2013. Forming and exploiting opportunities: The implications of discovery and creation processes for entrepreneurial and organizational research. Organization Science, 24: $301-317$.

Aspara J, Hietanen J, Tikkanen H (2010) Business model innovation vs replication: financial performance implications of strategic emphases. Journal Strategy Marketing 18(1):39-56.

Bacq, S., \& Janssen, F. (2011). The multiple faces of social entrepreneurship: A review of definitional issues based on geographical and thematic criteria. Entrepreneurship and Regional Development, 23, 373-403

Byrne J, Fayolle A and Toutain O (2014) Entrepreneurship education: What we know and what we need to know. In: Chell E and Karataş-Özkan M (eds) Handbook of Research on Small Business and Entrepreneurship. Cheltenham: Edward Elgar, pp.261-288.

Casillas, J.C., Moreno, A.M., Acedo, F.J., Gallego, M.A., Ramos, E., 2009. An integrative model of the role of knowledge in the internationalization process. Journal of World Business 44 (3), 311-322.

Chandra, Y., Styles, C., Wilkinson, I., 2009. The recognition of first time international entrepreneurial opportunities: evidence from firms in knowledge-based industries. International Marketing Review 26 (1), 3061.

Chigrin, O., T. Pimonenko, (2014), The Ways of Corporate Sector Firms Financing for Sustainability of Performance. International Journal of Ecology \& Development. Volume 29. Issue number 3. P. 1-13.

Chygryn O., (2016) The mechanism of the resource-saving activity at joint stock companies: the theory and implementation features. International Journal of Ecology \& Development. Volume 31. Issue number 3. P. 42-59.

Dacin, and Tracey(2011). Social Entrepreneurship: A Critique and Future Directions. Organization Science 22(5), pp. 1203-1213 
EKONOMI BISNIS DAN KEWIRAUSAHAAN

Vol. VIII, No. 1, Januari 2019

Dacin, P. A., M. Dacin, M. Matear. 2010. Do we need a theory of social entrepreneurship? Academy Management Perspective. 24(3) 37-57.

Doz YL, Kosonen M (2010) Embedding strategic agility: a leadership agenda for accelerating business model renewal. Long Range Plan 43(2-3):370-382.

Edwards P, Ram M, Jones T, Doldor S.(2016). New migrant businesses and their workers: developing, but not transforming, the ethnic economy. Ethnic and Racial Studies 39(9) :1587 - 1617.

Farinelli, F., Bottini, M., Akkoyunlu, S., \&Aerni, P. (2011). Green entrepreneurship: the missing link towards a greener economy. ATDF Journal, 8(3/4), 42-48.

Fayolle A (2013) Personal views on the future of entrepreneurship education. Entrepreneurship and Regional Development 25(7-8): 692-701.

Fayolle A (2013) Personal views on the future of entrepreneurship education. Entrepreneurship and Regional Development. 25(7-8): 692-701.

Fillis, I., \& Rentschler, R. (2010). The Role of Creativity in entrepreneurship. Journal of Enterprising Culture, 18(01), 49-81. doi:10.1142/s0218495810000501

Foss NJ, Saebi T (2018) Business models and business model innovation: between wicked and paradigmatic problems. Long Range Plan 51(1):9-21.

Ge L and Peng XM (2012) Research fronts of international entrepreneurship education in the visual threshold of knowmetrics. Journal of KnowledgeBased Innovation in China 4(1): 55-65.

Gevrenova. T. 2015. Nature and Characteristics of Green Entrepreneurship. Trakia Journal of Sciences, Vol. 13, Suppl. 2, pp 321- 323. ISSN 13137050 (print), ISSN 1313-3551 (online).

Guo H, Tang J, Su Z, Katz JA (2017) Opportunity recognition and SME performance: the mediating effect of business model innovation. $R \& D$ Management 47(3):431-442.

Guziana, B. (2011). Is the Swedish environmental technology sector 'green'?, Journal of Cleaner Production, 19:827-835.

Hall, J.K., Daneke ,G.A. кal Lenox M.J., (2010), Sustainable development and entrepreneurship: Past contributions and future direction, Journal of Business Venturing, 25:439-448.

Huybrechts, B., \& Nicholls, A. (2012). Social Entrepreneurship: Definitions, Drivers and Challenges. Social Entrepreneurship and Social Business, 3148. doi:10.1007/978-3-8349-7093-0_2

Jones, M. V., Coviello, N., \& Tang, Y. K. (2011). International Entrepreneurship research (1989-2009): A domain ontology and thematic analysis. Journal 
EKONOMI BISNIS DAN KEWIRAUSAHAAN

Vol. VIII, No. 1, Januari 2019

of $\quad \begin{aligned} & \text { Business } \\ & \text { doi:10.1016/j.jbusvent.2011.04.001 }\end{aligned}$

Keupp, M.M., Gassmann, O., 2009. The past and the future of international entrepreneurship: a review and suggestions for developing the field. Journal of Management 35 (3), 600-633.

Littlewood, D., \& Holt, D. (2015). Social Entrepreneurship in South Africa: Exploring the Influence of Environment. Business \& Society, 57(3), 525561. doi:10.1177/0007650315613293

Mainela, T., Puhakka, V., 2009. Organizing new business in a turbulent context: opportunity discovery and effectuation for IJV development in transition markets. Journal of International Entrepreneurship 7 (2), 111-134.

Martin, B. C., McNally, J. J., \& Kay, M. J. (2013). Examining the formation of human capital in entrepreneurship: A meta-analysis of entrepreneurship education outcomes. Journal of Business Venturing, 28(2), 211-224. doi:10.1016/j.jbusvent.2012.03.002.

Mwasalwiba ES (2010) Entrepreneurship education: A review of its objectives, teaching methods, and impact indicators. Education + Training 52(1): 2047.

Naia A, Rui B, Januario C, et al. (2014) A systematization of the literature on entrepreneurship education in higher education: Challenges and emerging solutions in the entrepreneurial classroom. Industry \& Higher Education 28(2): 79-96.

Neck HM and Greene PG (2011) Entrepreneurship education: Known worlds and new frontiers. Journal of Small Business Management 49(1): 55-70.

Neville F, Orse B, Riding A, Jung O (2014) Do young firms owned by recent immigrants outperform other young firms? Journal Business Venture. 29(1):55-71. https://doi.org/10.1016/i.jbusvent.2012.10.005

Nikolaou, E. I., Ierapetritis, D., \&Tsagarakis, K. P. (2011).An evaluation of the prospects of green entrepreneurship development using a SWOT analysis. International Journal of Sustainable Development \& World Ecology, 18(1), 1-16.

Oke, A., Munshi, N. and Walumbwa, F. O. (2009). The influence of leadership on innovation processes and activities. Organizational Dynamics 38(1):64-72.

Onetti A, Zucchella A, Jones MV, McDougall-Covin PP (2012) Internationalization, innovation and entrepreneurship: business models for new technology-based firms. Journal Management Governance.16(3):337-368 
EKONOMI BISNIS DAN KEWIRAUSAHAAN

Vol. VIII, No. 1, Januari 2019

Oosterbeek, H., van Praag, M., Ysselstein, A., 2010. The impact of entrepreneurship education on entrepreneurship skills and motivation. European Economic Review 54 (3), 442-454.

Ram M, Jones T (2008) Ethnic-minority businesses in the UK: a review of research and policy developments. Environment and Planning C: Government and Policy 26(2):352-374. https://doi.org/10.1068/c0722

Schneider S, Spieth P (2013) Business model innovation: towards an integrated future research agenda. International Journal Innovation Management 17(1):1-34

Shen S, H. Wang and X. Shi, "An Empirical Analysis of Interrelationship between Income, Health and Entrepreneurship," Technology and Investment, Vol. 4 No. 1B, 2013, pp. 18-23. doi: 10.4236/ti.2013.41B004.

Thompson, N., Kiefer, K., \& York, J. G. (2011). Distinctions not dichotomies: exploring social, sustainable, and environmental entrepreneurship. In Social and sustainable entrepreneurship (pp. 201-229). Emerald Group Publishing Limited.

Van Den Broeck, H, Cools, E. and Maenhout, T. (2008). A case study of arteconomy:Building bridges between art and enterprise: Belgian businesses stimulate creativity and innovation through art. Journal of Management and Organization 14:573-587.

Zahra, S. A., Gedajlovic, E., Neubaum, D. O., \& Shulman, J. M. (2009). A typology of social entrepreneurs: Motives, search processes and ethical challenges. Journal of Business Venturing, 24(5), 519-532.

Zahra, S.A., Ucbasaran, D., Newey, L.R., 2009. Social knowledge and SMEs' innovative gains from internationalization. European Business Review 6 (1), 81-93.

Zott C, Amit R (2010) Business model design: an activity system perspective. Long Range Plan 43(2-3):216-226

Zucchella A, Hagen B, Serapio M (2018) International entrepreneurship. Edward Elgar Publishing Limited, Cheltenham, pp 37-67 